\title{
Effect of Concurrent Engineering on Benefits of Product Development in Two Wheeler Automobiles
}

\author{
SIRIVELLA VIJAYA BHASKAR \\ ${ }^{1}$ Principal \& Professor, D BSIT, Kavali, Nellore, AP - 524201, AP, India \\ sbvijay2003@yahoo.com
}

\begin{abstract}
In today's highly competitive business environment, introducing a new product with expectation of high level of customer satisfaction is an intricate and immense challenge to the companies. Concurrent Engineering has a great deal of importance in design and development of new products in Indian automobile industry and is posing a big challenge to Indian firms in the wake of globalization. Success of concurrent engineering demands that major areas of product design and development of an organization are kept in focus concomitantly. The aim of the paper is to assess and establish the benefits of concurrent engineering in the new product design and development. The survey presents its evaluation based on the data analysis using cumulative weighed average with the help of primary data which was collected through a pre-tested questionnaire. The findings reveal that the two wheeler manufacturing companies in India are realizing maximum benefits with the implementation of the concurrent engineering in new product design and development. The research further recommends that companies must focus on weak areas of design and development in order to enhance the productivity.
\end{abstract}

Keywords: Concurrent Engineering, New Product Development, Production, Planning and Control, Process Management.

\section{Introduction}

In today's highly competitive global business world, the firms must be able to react quickly and responsively to the changing market needs. Moreover, they must be able to significantly reduce their time to market and adapt to the changing business environments, because of product's shorter life period. Therefore, concurrent engineering has emerged as way of bringing rapid solutions to product design and development process.

Concurrent engineering is indisputably the wave of the future for new product development for all companies regardless of their size, sophistication, or product portfolio. In order to be competitive, firms must alter their product and process development cycle to be able to complete diverse tasks concurrently. This new process will benefit the company, although it will require a large amount of refinement in its implementation. This is because concurrent engineering is a process that must be reviewed and adjusted for continuous improvements of engineering and business operations.

According to Nielsen (2003)[1], concurrent engineering is the simultaneous consideration of more than one aspect of a system during its design phase. Concurrent Engineering is a system of practices that provides the environment for design engineering and production departments work together, which enhances productivity and leads to high-class designs. The study of concurrent engineering (CE) and its implementation has been the greatest themes in the engineering sciences. Many disciplines have developed theoretical literature and empirical findings about the origin, development, transformation, decay, and decline of the system. Concurrent Engineering defined as "a business strategy which replaces the traditional product development process with one in which tasks is done in parallel and there is an early consideration for every aspect of a product's development process". This strategy focuses on the optimization and distribution of a firm's resources in the design and development process to ensure effective and efficient product development process.

\section{Literature Review}

Product design and development is a series of activities which are organized in a specific way in order to reach products that meets the requirements of a project. Most of these processes are iterative in order to evaluate and test ideas, concepts or proposals. Eppinger [2] et al., discussed about New Product Development (NPD) using concurrent engineering concept and revealed that new tools like concurrent engineering helps the firms to achieve effective satisfaction of customer needs and less time to penetrate the market. But the limitations of the use of these techniques needs changes in organizational set up, and create adverse effects. As responsiveness and agility are becoming important competitive attributes in addition to quality, variety and price, this leads to many companies to simultaneously compete in the three domains of product, process, and supply chain to maximize the operational and supply chain performance [3-4]. On the other hand, Mass Customization is a business strategy to bring together, under the same production system, the competitive advantages of product customization and the efficiencies associated with "mass productio. A firm's organizational structure often mirrors the product structure of the products the firm produces [7]. Thus, the design decision on the number and size of 
'chunks' (subsystems, modules, parts, etc.), i.e., the functioncomponent allocation scheme, translates into the number and size of teams working to develop the product. The number and size of the teams determines their internal complexity as well as their external communication requirements. Both factors in turn determine the teams' level of efficiency. Design for manufacturing (DFM) aims at simplifying manufacturing processes, which results-in addition to lower investment-in reduction of process variability and ultimately in faster process rates and higher yields, and thus lower cost. In contrast, DFA generally emphasizes part count reduction, the use of only one assembly direction and the preference of symmetrical parts (Boothroyd et al. 2002) [5].

Reducing the risks of new product development by implementing proven technologies at the core of the new product is very essential. The figure 1 shows the product development life cycle.

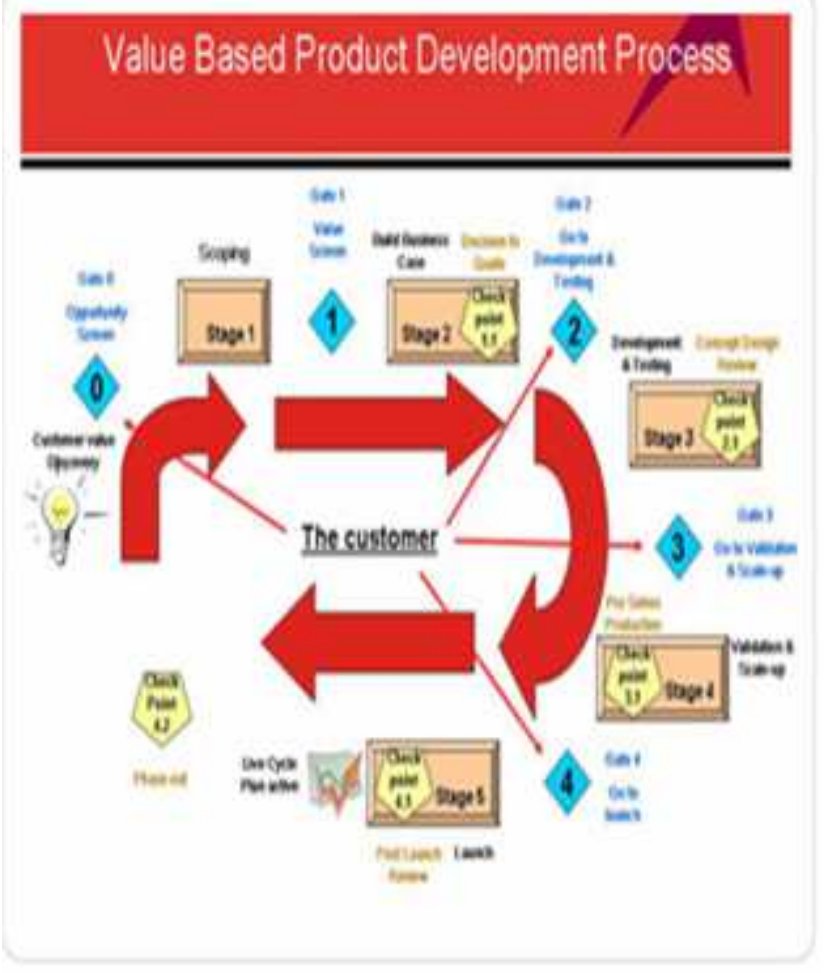

Fig 1. Product Development Process

Concurrent engineering replaces the more traditional sequential design flow, or Waterfall Model. In concurrent engineering an iterative or integrated development method is used instead. The difference between these two methods is that the 'Waterfall' method moves in a linear fashion by starting with user requirements and sequentially moving forward to design, implementation and additional steps until you have a finished product. In this design system, a design team would not look backwards or forwards from the step it is on to fix possible problems. In the case that something does go wrong, the design usually must be scrapped or heavily altered. On the other hand, the iterative design process is more cyclic in that, all aspects of the life cycle of the product are taken into account, allowing for a more evolutionary approach to design.
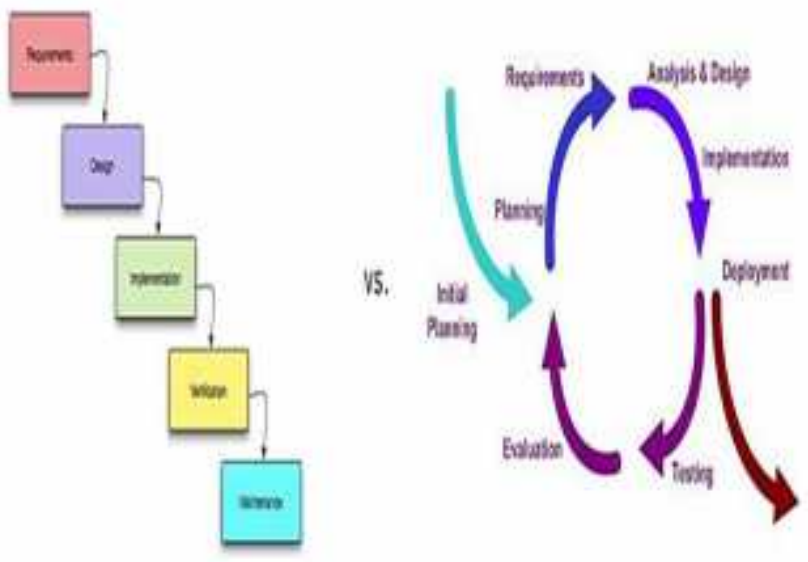

Fig 2. Sequential vs. Iterative Development Method

\section{Purpose of the Study}

The objective of the research study is to investigate and establish the impact of concurrent engineering on product design and development of Indian two wheeler automobile industries.

\section{A. Methodology}

The evaluation of the study is based on a data analysis of the primary data using Cumulative Weighted Average statistical analysis technique. The primary data was collected through a well-structure questionnaire from the 91 respondents of design, production and marketing groups of two wheeler manufacturing companies in India. The questionnaire was sent to 200 respondents of 3 automobile companies of Chennai and the usable response rate was $45 \%$ (see the Table 1 ).

\section{Table-1}

Response Rating of the Survey

\begin{tabular}{|c|c|c|c|}
\hline \multirow{2}{*}{$\begin{array}{c}\text { Type of } \\
\text { organization }\end{array}$} & \multicolumn{2}{|c|}{$\begin{array}{c}\text { Number of } \\
\text { Organizations }\end{array}$} & \multirow{2}{*}{$\begin{array}{c}\text { Response } \\
\text { Ratio } \\
\text { (in \%) }\end{array}$} \\
\hline & $\begin{array}{l}\text { Question- } \\
\text { naire Sent to }\end{array}$ & $\begin{array}{l}\text { Response } \\
\text { Received }\end{array}$ & \\
\hline $\begin{array}{l}\text { Two Wheeler } \\
\text { Industry } \\
\text { Automobile } \\
\text { manufacturers }\end{array}$ & 03 & 03 & $100 \%$ \\
\hline No. of Respondents & 200 & 91 & $45 \%$ \\
\hline
\end{tabular}




\section{B. Data Analysis and Interpretation}

The data pertaining to the benefits of concurrent engineering in new product development in two wheeler manufacturing companies are presented in the Table 2 and the same is depicted in the Figure 1.

The scores of CWA that are determined from the primary data are plotted on a radar diagram as illustrated in Figure 3 , which summarizes the affect of each factor.

The data presented in the Table 2, clearly establishes that the realized benefits of concurrent engineering in new product development of two wheeler companies is considerably high.
In specific, the variables of benefits with CWA score of greater than 3.5 on a 5-point scale: Contribution in reduction of time to market, Ensuring competitive ma position, Optimum Resource Allocation, Improvement in production planning process, Improvement in communication and collaboration between departments, Effective establishment of cross-functional integration and Alignment with strategic plans are identified as major areas that realized maximum benefits. Generally product design, manufacturing process design, and supply chain design decisions are interrelated domains.

Table- 2:

Benefits of Concurrent Engineering - CWA Scores

\begin{tabular}{|l|c|}
\hline \multicolumn{1}{|c|}{ Factors that Affecting the Benefits of Concurrent Engineering } & CWA \\
\hline Contribution in reduction of time to market & 3.82 \\
Increased cost savings & 2.92 \\
Ensuring competitive market position & 3.84 \\
Optimum Resource Allocation & 3.71 \\
Improvement in production planning process & 3.58 \\
Improvement in communication and collaboration between departments & 3.67 \\
Effective establishment of cross-functional integration & 3.57 \\
Identification of appropriate cutting-edge technologies in proto-typing & 2.98 \\
Alignment with strategic plans & 3.47 \\
\hline \multicolumn{1}{|c|}{ Average CWA } & $\mathbf{3 . 5 1}$ \\
\hline
\end{tabular}

(Source: Field Survey)

CWA: Cumulative Weighted Average

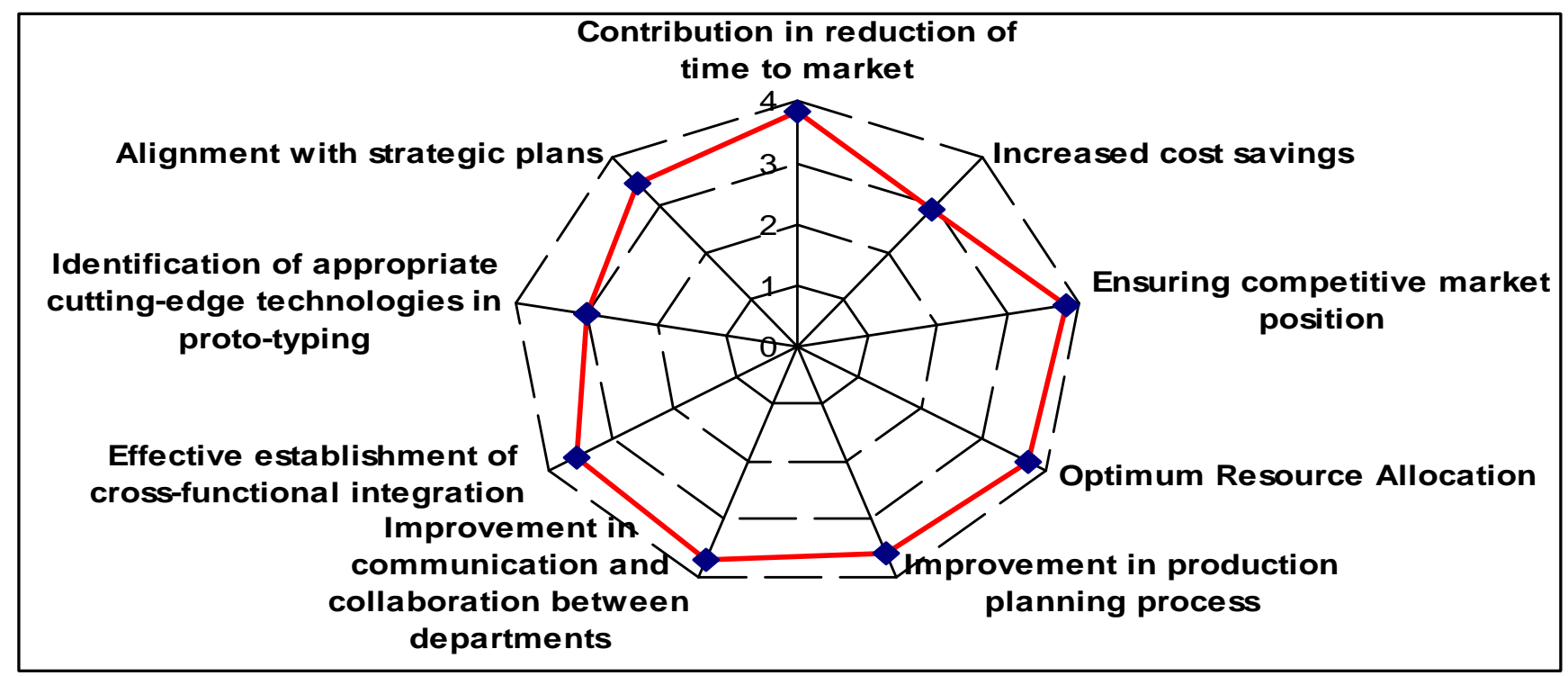

Fig.3: Realization Benefits of CE in Automobile industry 


\section{Results and Discussion}

Concurrent engineering has very positive impact on design and development of new product in two wheeler automobile companies. Although companies that implementing concurrent engineering is able to realize maximum benefits, they need to focus their attention in identifying the appropriate cutting-edge technologies for proto-typing and thus increased the cost savings on product development.

\section{References}

[1] Nielsen, J., (2003), "Information Modeling of Manufacturing Processes: Information requirements for process planning in a concurrent engineering environment", Doctoral Thesis, KTH Production Engineering, TRITA-IIP-02-09, ISSN 1650-1888.

[2] Eppinger. S.D., Whitney, D.E., Smith, R.P., Gebala. D.a, "A ModelBased Method for Organizing Tasks in Product Development, Research in Engineering Design", [4] Rosenblatt, A. and Watson, G., "Concurrent Engineering", IEEE Spectrum, July, 1991, pp 22-37.

[3] Boothroyd, Geoffrey, Peter Dewhurst, and Winston Knight, "Product Design for Manufacture and Assembly", 2nd ed. New York: Marcel Dekker, 2002.

[4] Liker, J.K., 'The Toyota Way: 14 Management Principles from the World's Greatest Manufacturer', New York: McGraw-Hill., Feld, W.M., 2001.

[5] Clark K.B., Wheelwright S.C., "Managing new product development Text and Cases", Harvard Business School, 1993.

[6] Richard Badham, Paul Couchman, and Michael Zanko, "Implementing Concurrent Engineering", 1996. [4] Cooper, 